\title{
A JAPANESE FAMILY PEDIGREE OF PATIENTS WITH SEVERE COMBINED IMMUNODEFICIENCY DISEASE WITH X-LINKED INHERITANCE
}

\author{
Masayoshi Minegishi, Shigeru TsuchiYa, Yoshiko Yamaguchi, \\ Tetsuo SATo, Naoko Minegishi, and Tasuke Konno \\ Department of Pediatrics, Research Institute for Tuberculosis and Cancer, \\ Tohoku University, Aoba-ku, Sendai 980, Japan
}

\begin{abstract}
Summary We described three patients with severe combined immunodeficiency disease (SCID) with B lymphocytes from a single family. Adenosine deaminase and purine nucleoside phosphorylase activities were normal. Two of them received bone marrow transplantation from an HLA haplotype-mismatched mother and an HLA-identical sibling, respectively, with successful immunological reconstitution. Another patient died of severe pneumonia. X-linked inheritance was suggested through the analysis of the pedigree extending four generations. This is probably the largest SCID kindred reported in Japan.
\end{abstract}

Key Words family pedigree, severe combined immunodeficiency disease, X-linked inheritance, bone marrow transplantation

\section{INTRODUCTION}

Severe combined immunodeficiency disease (SCID) represents a spectrum of disorders characterized by the inability to manifest normal cell-mediated and humoral immunity (Gelfand and Dosch, 1983). The heterogeneity of the disease may be attributable to a number of abnormalities in the quantitative and qualitative differentiation and maturation of primary lymphoid stem cells (Gelfand and Dosch, 1983). The majority of affected infants usually die before their first or second birthday, unless an immunologic reconstitution is successfully undergone. The majority of cases occur as isolated events, although there have been some reports of families that have autosomal recessive or X-linked inheritance (Gelfand and Dosch, 1983). In this paper, we describe three SCID patients originating from a single family, representing $X$-linked inheritance by informative findings. Two of them received bone marrow transplantation (BMT) with successful immunologic reconstitution.

Received, December 12, 1990; Accepted April 1, 1991. 


\section{CASE REPORT}

Patient 1. The BMT case history was previously reported elsewhere (Minegishi et al., 1985). Briefly, a 6-month-old male patient (A.Y.), was initially referred to the Tohoku University Hospital because of refractory oral thrush, chronic cough, recurrent otitis media and failure to thrive in August, 1982. Two maternal uncles had died in their infancy, one of pneumonia and another of candidiasis. No thymic shadow, tonsils or lymph nodes were detected. The diagnosis of SCID with B cells was made on the basis of the following findings : a numerical deficiency of T lymphocytes, absence of in vitro transformation responses to phytohemagglutinin (PHA), concanavalin A (Con A), pokeweed mitogen (PWM) and allogeneic cells, anergy to candida, purified protein derivative (PPD) and streptokinase/streptodornase (SK/SD) skin tests, and profound hypogammaglobulinemia (Table 1).

Table 1. Immunophenotypic findings of the peripheral blood lymphocytes and serum immunoglobulins of the SCID patients.

\begin{tabular}{|c|c|c|c|}
\hline & Patient 1 (A.Y.) & Patient 2 (M.G.) & Patient 3 (Y.O.) \\
\hline Lymphocyte $\left(/ \mathrm{mm}^{3}\right)$ & 4,680 & 1,998 & 2,866 \\
\hline $\mathrm{CD} 1(\%)$ & 0 & 0 & ND \\
\hline $\mathrm{CD} 2(\%)$ & ND & ND & $0 \quad(2.2)^{\mathrm{a}}$ \\
\hline $\mathrm{CD} 3(\%)$ & 5.0 & 0 & $0(0)$ \\
\hline $\mathrm{CD} 4(\%)$ & 1.0 & 0 & $0(0)$ \\
\hline $\mathrm{CD} 5(\%)$ & ND & ND & $2.3(6.7)$ \\
\hline $\mathrm{CD} 7 \%$ & ND & ND & $\mathrm{ND}(0)$ \\
\hline $\mathrm{CD} 8(\%)$ & 0 & 0 & $0(0)$ \\
\hline $\operatorname{CD} 19(\%)$ & ND & ND & $95.9(74.9)$ \\
\hline $\mathrm{CD} 20(\%)$ & 63.0 & 62.3 & $96.3(74.2)$ \\
\hline $\mathrm{CD} 57(\%)$ & ND & ND & ND ( 0$)$ \\
\hline HLA-DR $(\%)$ & ND & 81.5 & $96.9(84.2)$ \\
\hline $\operatorname{TCR} \alpha / \beta(\%)$ & ND & ND & $\mathrm{ND}(1.2)$ \\
\hline $\operatorname{S-Ig}(\%)$ & 65.8 & 65.7 & ND \\
\hline$\mu$-chain $(\%)$ & 58.8 & ND & 58.5 \\
\hline 8 -chain $(\%)$ & 57.1 & $\mathrm{ND}$ & 85.9 \\
\hline$\gamma$-chain $(\%)$ & 0 & ND & 0 \\
\hline$\alpha-\operatorname{chain}(\%)$ & 0 & ND & 0 \\
\hline$x$-chain $(\%)$ & 36.3 & ND & 59.2 \\
\hline$\lambda$-chain $(\%)$ & 43,3 & ND & 43.4 \\
\hline \multicolumn{4}{|c|}{ Serum immunoglobulins } \\
\hline $\operatorname{IgM}(\mathrm{mg} / \mathrm{dl})$ & 0 & 25 & 50 \\
\hline $\operatorname{IgG}(\mathrm{mg} / \mathrm{dl})$ & 12 & $<80$ & 183 \\
\hline $\operatorname{IgA}(\mathrm{mg} / \mathrm{d} 1)$ & 0 & $<8$ & 24 \\
\hline
\end{tabular}

Abbreviations: SCID, severe combined immunodeficiency disease; $\mathrm{CD}$, cluster of differentiation; TCR, T cell receptor; S-Ig, surface immunoglobulins; ND, not done. a Data inparentheses showed those in bone marrow samples of Patient 3. 
Adenosine deaminase (ADA) and purine nucleoside phosphorylase (PNP) activities in red cells were normal. At the age of 5 months he had had a BCG vaccination without any local or systemic response.

As previously reported elsewhere (Minegishi et al., 1985) he underwent HLAhaplotype mismatched BMT using soybean agglutinin- and sheep red blood cellfractionated maternal marrow, the engraftment being achieved without apparent graft-versus-host disease (GVHD). With immunological reconstitution the patient recovered from a BCG infection, which might have been caused by a BCG inoculation before his BMT. The patient is now in excellent health at 8 years posttransplantation.

Patient 2. On March 1, 1985, a 7-month-old male infant suspected to primary immunodeficiency disease was referred to our Hospital. He had been uneventfully delivered after a full-term pregnancy. An intractable skin rash on the cervical and perineal regions developed at the age of 2 months, persistent cough and stridor at $3 \frac{1}{2}$ months and pneumonia at 7 months. Laboratory data on admission revealed profound hypogammaglobulinemia (Table 1) and a lack of lymphocytes reacting with monoclonal antibodies (MoAbs) to T-cell antigens. Proliferative responses to mitogens were absent. ADA and PNP activities in red cell were within normal limits. Four days after the admission he died of progressive pneumonia.

Patient 3. In January 1989, a 4-month-old male infant suspected of primary immunodeficiency disease was referred to our Hospital. He was born uneventfully at term, weighing $3,700 \mathrm{~g}$. Since two months of age he had had intractable cough and stridor, associated with recurrent skin eruptions and brief episodes of diarrhea. He also had otitis media at 3 months and pneumonia at 4 months of age. No thymic shadow, tonsils or lymph nodes were detected. He had profound hypogammaglobulinemia (Table 1). Immunologic examinations revealed the absence of $T$ lymphocytes, and their failure to proliferate in responses to mitogens. ADA and PNP activities in red cells were within normal limits.

On January 20, 1989, he underwent HLA identical BMT from his healthy brother; a total of $5.25 \times 10^{9}$ nucleated donor marrow cells $\left(7.83 \times 10^{8}\right.$ cells per $\mathrm{kg}$ body weight) were infused intravenously. Cyclosporin A was used for GVHD prophylaxis. At one week post-grafting, the monilial diaper rash became more erythematous and there was an increased percentage of CD3-positive lymphocytes. Surface marker studies further showed an increase of CD4- and CD8-positive lymphocytes. Proliferative responses to mitogens were positive by two weeks posttransplantation. Significantly increased levels of serum $\operatorname{IgM}$ and $\operatorname{IgG}$ were found on day 250 and 290 post-transplantation, respectively. Natural killer (NK) activity, which was not detected on day 41, was detected on day 178 post-transplantation. The patient was discharged 10 weeks after BMT.

Immunophenotypic analyses. Surface antigens defined by MoAbs were analyzed by direct or indirect immunofluorescence as previously described (Minegishi et al., 1988). MoAbs used and their antigen targets (cluster designation, CD, in 
parentheses) were as follows: T6(CD1), T11(CD2), OKT3(CD3), T4(CD4), Leu1(CD5), Leu-9(CD7), T8(CD8), B4(CD19), B1(CD20), Leu-7(CD57), TCR-1 and HLA-DR. TCR- 1 is a MoAbs specific for a T cell receptor $\alpha / \beta$ chain determinant (Spits et al., 1985). MoAbs were obtained from the following sources: Leu series, TCR-1 and HLA-DR (Becton Dickinson, Mountain View, CA); T6, T11, T4, T8, B1, and B4 (Coulter Immunology, Hialeah, FL); OKT3 (Ortho Pharmaceutical Corp., Raritan, NJ). Surface membrane immunoglobulins (Ig) were detected with rabbit anti-human $\mu$ - and $\delta$-chain sera conjugated with fluorescein isothiocyanate (Behringwerke, Marburg-Lahn) (Tsuchiya et al., 1980).

The results of immunophenotypic analysis carried out with the use of various MoAbs are summarized in Table 1. Three patients had very few cells reacting with MoAbs to T-cell antigens, but there was an increase in the number of B cells defined by surface Ig and MoAbs such as CD19 and CD20, although serum Ig levels were hardly detectable. The diagnosis of SCID with B cells was made in all three patients.

\section{PEDIGREE ANALYSIS}

The family pedigree of the patients with SCID is shown ig Fig. 1. Because two maternal uncles of patient 1 (A.Y., IV/25) had died in their infancy, one (III/ 17) of pneumonia at 3 months of age and another (III/19) of generalized cnadidiasis

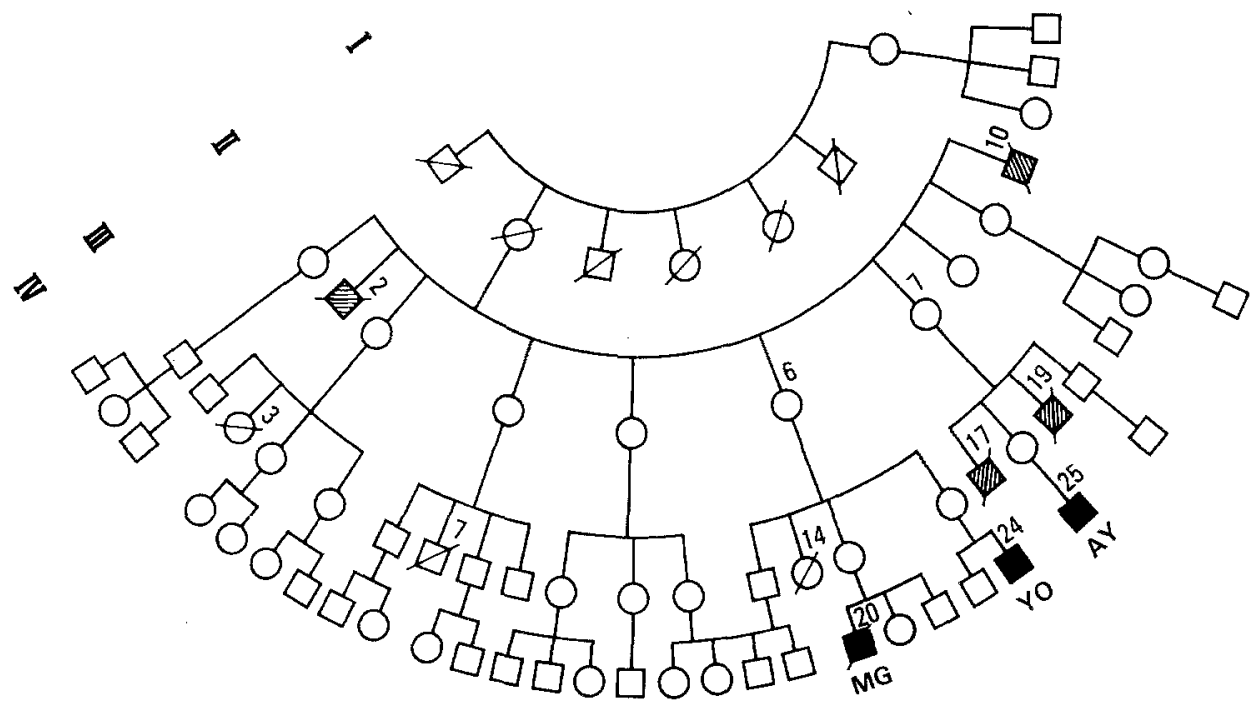

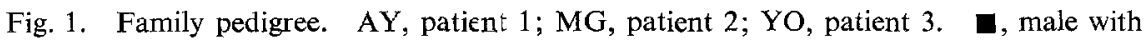
SCID; 䇣後, deceased child: SCID status unknown. Mother of patients 2 and 3 were siblings, and grandmothers of three SCID patients were also siblings. Their two male siblings (II/2 and $\mathrm{II} / 10$ ) and two maternal uncles (III/17 and $\mathrm{III} / 19)$ of the patient 1 had died in infancy. 
at 10 months of age, the underlying disease was suspected to be of X-linked inheritance. The mothers of patients 2 (M.G.) and 3 (Y.O.) were found to be siblings. In further quest of their family history, it was revealed that two other males (II/2 and II/10) who were siblings of the grandmothers of the patients reported in the present study had died in infancy (II/2 at 1 year of age and II/10 at 1 week of age) of unknown cause. No immunological problems have been discovered among the descendants of eight of the II siblings, patients clustering among the progeny of II/6 and II/7. Two other females (III/3 and III/14) died in their infancy of flulike infection and severe colitis, respectively, but they were reported to have had no history of recurrent infections before the last episodes. One male (III/7) had been drowned. These informative findings obtained from the family history suggested a genetic evidence for the disease.

\section{DISCUSSION}

SCID is a term used to describe a heterogeneous group of genetic disorders in which there are profound defects in both cellular and humoral immunity (Gelfand and Dosch, 1983). Most patients with SCID have markedly reduced numbers of $\mathrm{T}$ cells, absent proliferative responses to mitogens, hypogammaglobulinemia, and heterogenous numbers of $\mathrm{B}$ cells, ranging from complete absence to increased proportions (Ammann and Hong, 1989; Rosen et al., 1986). The immunological findings in three SCID patients reported here were characterized by a low number of $\mathrm{T}$ cells, absent mitogenic responses, hypogammaglobulinemia, the presence of B lymphocytes which had $\mu$ and $\delta$ heavy chains on their surface, and normal activities of ADA and PNP. These common features in the three patients may suggest a relationship to the genetic background of the pathogenesis of the disease.

When affected males outnumber females by a ratio of about $4: 1$, X-linked inheritance of the illness has been suggested. However, only $20-30 \%$ of affected boys have a family history of immunodeficiency (Gelfand and Dosch, 1983). Few Japanese SCID family pedigrees have been reported to our knowledge. We described three patients with SCID belonging to a large kindred. Two of them received BMT with immunological reconstitution. Another patient died of progressive pneumonia before BMT. Informative investigations revealed that in this kindred four male children $(\mathrm{II} / 2, \mathrm{II} / 10, \mathrm{III} / 17, \mathrm{III} / 19)$ had died in their infancy, suggesting an $\mathrm{X}$-linked inheritance of their illness. There were two females who died in their early childhood, but they had no history of severe infection before the episodes which led them to death. Collectively, the family reported in this paper is probably the largest kindred of SCID with X-linked inheritance in Japan.

Two of the patients underwent BMT with successful immunological reconstitution; one with HLA-haplotype mismatched marrow and another with HLAidentical marrow. These resuits confirm other reports that in addition to HLAidentical donors, haplo-identical parental donors offer allogeneic BMT as a curative 
therapy for children with lethal SCID (Reisner et al., 1983; Friedrich et al., 1984).

Follow-up studies with this family may provide useful information for the understanding of gene defects that cause SCID. For the risks facing family members, besides therapeutic measures such as BMT, careful studies would be necessary, including prenatal diagnosis with the use of restriction fragment length polymorphisms linked to the gene for X-linked SCID, present on the proximal part of the long arm of the X chromosome (Puck et al., 1989; de Saint Basile et al., 1987).

Acknowledgments. Supported in part by a Research Grant from the Ministry of Education, Science and Culture of Japan.

\section{REFERENCES}

Ammann, A.J. and Hong, R. 1989. Disorders of the T cell system. In Immunologic Disorders in Infants and Children, Stiehm, E.R., ed., W.B. Saunders Company, Philadelphia, pp. 257-315.

de Saint, Basile, G., Arveiler, B., Oberle, I., Malcolm, S., Levinsky, R.J., Lau, Y.L., Hofker, M., Debre, M., Fischer, A., Griscelli, C. and Mandel, J.L. 1987. Close linkage of the locus for $\mathrm{X}$ chromosome-linked severe combined immunodeficiency to polymorphic DNA markers in Xq11-q13. Proc. Natl. Acad. Sci. U.S.A. 84: 7576-7579.

Friedrich, W., Goldmann, S.F., Vetter, U., Fliedner, T.M., Heymer, B., Peter, H.H., Reisner, Y. and Kleinhauer, E. 1984. Immunoreconstitution in severe combined immunodeficiency after transplantation of HLA-haploidentical, T-cell-depleted bone marrow. Lancet 1: 761-764.

Gelfand, E.W. and Dosch, H.-M. 1983. Diagnosis and classification of severe combined immunodeficiency disease. Birth Defects Orig. Artic. Ser. 19: 65-72.

Minegishi, M., Tsuchiya, S., Imaizumi, M., Yamaguchi, Y., Goto, Y., Tamura, M., Konno, T. and Tada, K. 1985. Successful transplantation of soybean agglutinin-fractionated, histoincompatible, maternal marrow in a patient with severe combined immunodeficiency and BCG infection. Eur. J. Pediatr. 143: 291-294.

Minegishi, M., Tsuchiya, S., Minegishi, N., Yoshie, O., Nakamura, M. and Konno, T. 1988. Characterization of a precursor T-cell line (THP-6) with rearranged T-cell receptor $\beta$-chain gene. Leuk. Res. 12: 227-232.

Puck, J.M., Nussbaum, R.L., Smead, D.L. and Conley, M.E. 1989. X-linked severe combined immunodeficiency: localization within the region Xq13.1-q21.1 by linkage and deletion analysis. Am.J. Hum. Genet. 44: 724-730.

Reisner, Y., Kapoor, N., Kirkpatrick, D., Pollack, M.S., Cunningham-Rundles, S., Dupont, B., Hodes, M.Z., Good, R.A. and O'Reilly, R.J. 1983. Transplantation for severe combined immunodeficiency with HLA-A, B, D, DR incompatible parental marrow cells fractionated by soy bean agglutinin and sheep red blood cells. Blood 61: 341-348.

Rosen, F.S., Wedgewood, R.J., Eibl, M., Aiuti, F., Cooper, M.D., Good, R.A., Griscelli, C., Hanson, L.A., Hitzig, W.H., Matsumoto, S., Seligman, M., Smoothill, J.F. and Waldman, T.A. 1986. Clin. Immunol. Immunopathol. 40: 166-196.

Spits, H., Borst, J., Tax, W., Capel, P., Terhorst, C. and de Vries, J. 1985. Characteristics of a monoclonal antibody (WT31) that recognizes a common epitope on the human T cell receptor for antigen. J. Immunol. 135: 1922-1928.

Tsuchiya, S., Konno, T., Tada, K. and Ono, Y. 1980. Epstein-Barr virus-induced lymphoblastoid cell lines from patients with primary immunodeficiency diseases. Scand. J. Immunol. 11: 155162. 